\title{
A long-lever spinal orthosis for idiopathic scoliosis: corrective potential in 10 patients
}

\author{
Brian Dovorany ${ }^{*}$, Mark Morningstar \\ From 10th International Conference on Conservative Management of Spinal Deformities - SOSORT 2013 \\ Annual Meeting \\ Chicago, IL, USA. 8-11 May 2013
}

\section{Background}

The long-lever orthosis was designed to treat large translational displacements associated with idiopathic scoliosis. Adding a long-lever system allows the practitioner to affect the spine with a relatively low amount of force, while changing the rotational displacement of scoliosis based upon its effect on the thoracic cage.

\section{Purpose}

The goal of this study was to determine whether a novel long-lever orthosis has the ability to positively impact idiopathic scoliosis.

\section{Methods}

A sample of 10 patients, ranging in age from 11 to 16 years, with adolescent idiopathic scoliosis presented to a private chiropractic clinic for evaluation and management. All 10 patients had double major scoliosis curve patterns and were fitted for a long-lever orthosis system. Once in place, scoliosis radiographs were obtained while wearing the orthoses. Outcome measurements included Cobb angle and rotational displacement

\section{Results}

The average baseline Cobb angles were $51^{\circ}$ thoracic (range $39-76^{\circ}$ ) and $31^{\circ}$ lumbar (range $23-41^{\circ}$ ). While wearing the long-lever orthosis system, the thoracic and lumbar Cobb angles decreased to an average of $28^{\circ}$ and $27^{\circ}$, respectively. In five of the patients tested, additional improvement in thoracic rotation was observed, by an average of $52 \%$ (range 12-97\%). No patient tested had an increase in curves or rotation while wearing the long-lever orthosis system.

\footnotetext{
* Correspondence: drdovorany@treatingscoliosis.com Spine \& Posture Center, Green Bay, WI USA
}

\section{Conclusions and discussion}

While wearing a specialized long-lever orthosis system, patients saw their Cobb angles and thoracic rotation decrease. This orthosis may help complement exercisebased scoliosis rehabilitation programs for patients with large translational displacements of the thoracic spine.

Published: 18 September 2013

\section{References}

1. Gabrielle C Lam, Doug L Hill, Lawrence H Le, Jim V Raso, Edmond H Lou: Vertebral rotation measurement: a summary and comparison of common radiographic and CT methods. Scoliosis 2008, 3:16.

2. Stokes IAF: Axial rotation component of thoracic scoliosis. J. Orthop. Res 1989, 7:702-708.

doi:10.1186/1748-7161-8-S2-O53

Cite this article as: Dovorany and Morningstar: A long-lever spinal orthosis for idiopathic scoliosis: corrective potential in 10 patients. Scoliosis 2013 8(Suppl 2):053.
Submit your next manuscript to BioMed Central and take full advantage of:

- Convenient online submission

- Thorough peer review

- No space constraints or color figure charges

- Immediate publication on acceptance

- Inclusion in PubMed, CAS, Scopus and Google Scholar

- Research which is freely available for redistribution
( Biomed Central 